\title{
Intraluminal diverticulum of the duodenum and choledochocele
}

\author{
F. J. BRUNTON AND J. BAMFORTH
}

From the Departments of Radiodiagnosis and Gastroenterology, Southampton University Group of Hospitals

SUMMARY An example of intraluminal diverticulum and another of choledochocele are reported. They both presented as abdominal emergencies in adult life, and the conditions are readily shown on barium studies.

Two examples of intraluminal mucosal abnormalities resembling a diverticulum are presented. They are different in type but have features in common. Although they would appear to have a congenital aetiology, they presented as emergencies in adult life.

\section{Case 1}

Mrs M.N., aged 34, was admitted having vomited continually for three days. Three and a half months previously she had successfully completed her fourth pregnancy although this pregnancy had been complicated by severe 'hyperemesis gravidarium'. The three previous pregnancies had been normal. Since the pregnancy she had been vomiting on and off and was now unable to retain any food. This last episode dated from eating some dried currants, and she was vomiting practically every hour bile-stained vomit. She also complained of central abdominal pain radiating to the right iliac fossa, and had been losing weight.

She was treated medically as an infant for pyloric stenosis, and had tended to have vomiting attacks during childhood.

The patient was very thin and dehydrated. A succession splash was present and peristaltic movements were heard in the abdomen. She was tender in the epigastrium.

Serum sodium was 137 m-equiv per litre, potassium 4.6 m-equiv per litre, chlorides $85 \mathrm{~m}$-equiv per litre, and bicarbonate (total $\left.\mathrm{CO}_{2}\right) 28$ m-equiv per litre.

The first barium meal showed an obstruction in the first part of the duodenum and an intraluminal diverticulum in the second part of the duodenum (Fig. 1). The diverticulum was filled with debris and was thought to be of diaphragm type.

Received for publication 21 December 1971.
An intravenous Biligrafin examination showed a normal common bile duct (diameter $1.0 \mathrm{~cm}$ ).

The patient's condition improved and the second barium meal pre-operatively five days later (Fig. 2) showed that the diverticulum was no longer filled

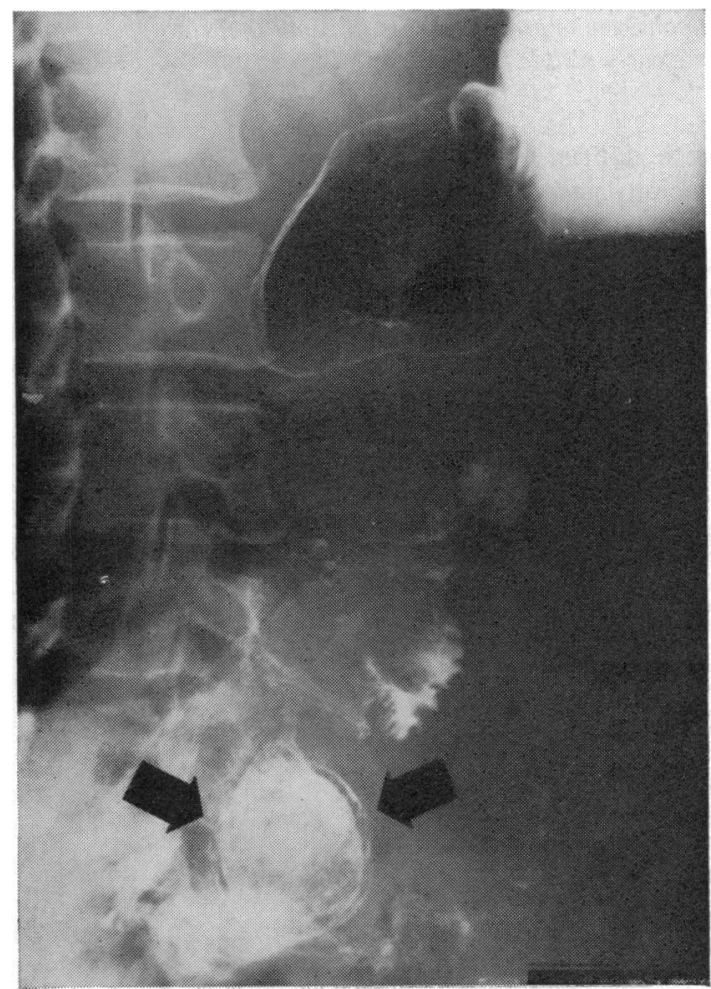

Fig. 1 Case 1: intraluminal diverticulum.

The diverticulum is propelled on a long 'stalk' down the duodenum, the distal part containing debris. The translucent wall can be seen arrowed. A little barium passes the obstruction (barium meal 1). 


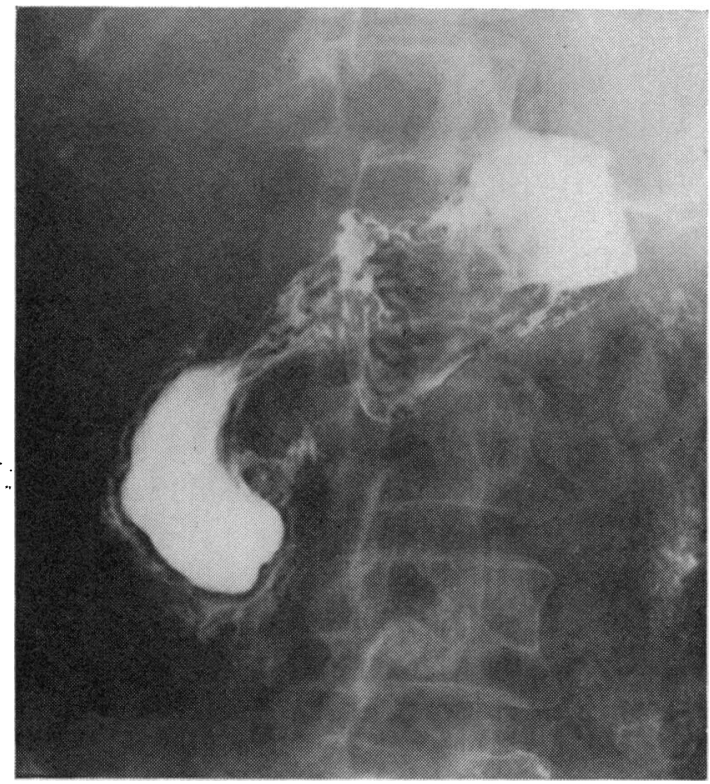

Fig. 2 Case 1: the acute symptoms had subsided. The diaphragm is prolapsed less far, and the translucent wall is clearly visible (barium meal 2).

with debris, was prolapsed much less far, and the barium passed more easily through into the distal duodenum. The barium was seen to pass through the obstruction on the medial side, about $3.0 \mathrm{~cm}$ proximal to the tip of the diaphragm.

At operation (Mr Rowntree) a duodenal mucosal stenosis was found. A small orifice was present on the medial side of the diaphragm close to the ampulla. The diaphragm was resected avoiding the common bile duct. The patient made an uneventful recovery.

Examination of the resected diaphragm (Dr Magnusson) showed a strap-like fragment covered on both aspects by mucosa $(7.0 \times 2.0 \times 0.2 \mathrm{~cm})$. Microscopy revealed normal duodenal mucosa with occasional Brunner's glands.

\section{Case 2}

J.G., a man aged 33, had had intermittent pain in the right side of the abdomen and chest following an injury five years previously. The pain was not severe and not related to food, although relieved by antacids. Seven days before admission he had vomited intermittently but this had ceased in the last three days. Six days and one day earlier the patient had passed melaena stools.

On examination, other than slight pallor, nothing significant was found.

Haemoglobin was $7 \cdot 1$ g (49\%), PCV $23 \%$, MCHC

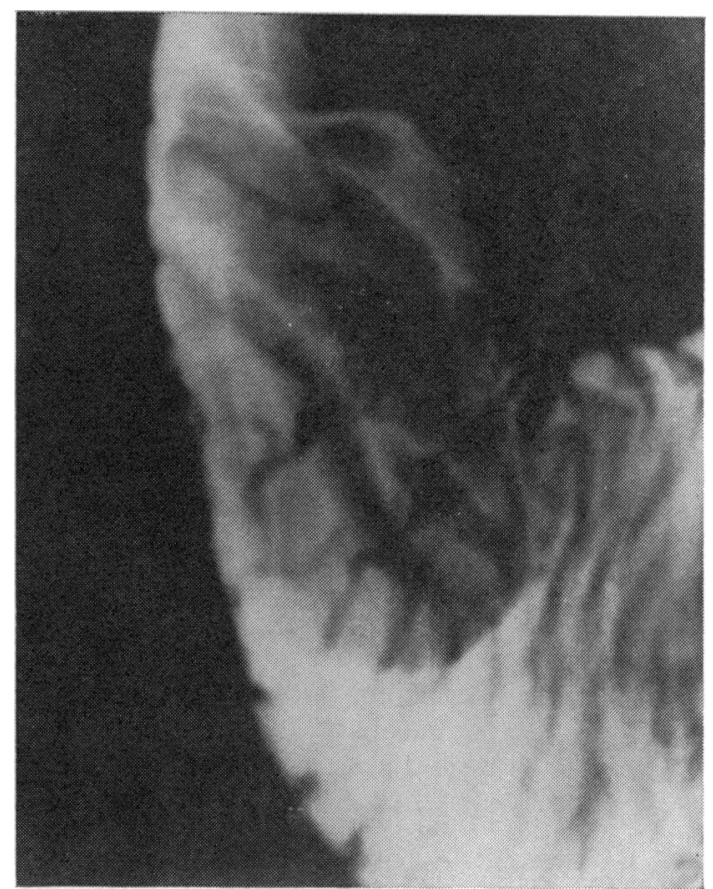

Fig. 3 Case 2: choledochocele. The intraluminal mass is shown with longitudinal folds (barium meal).

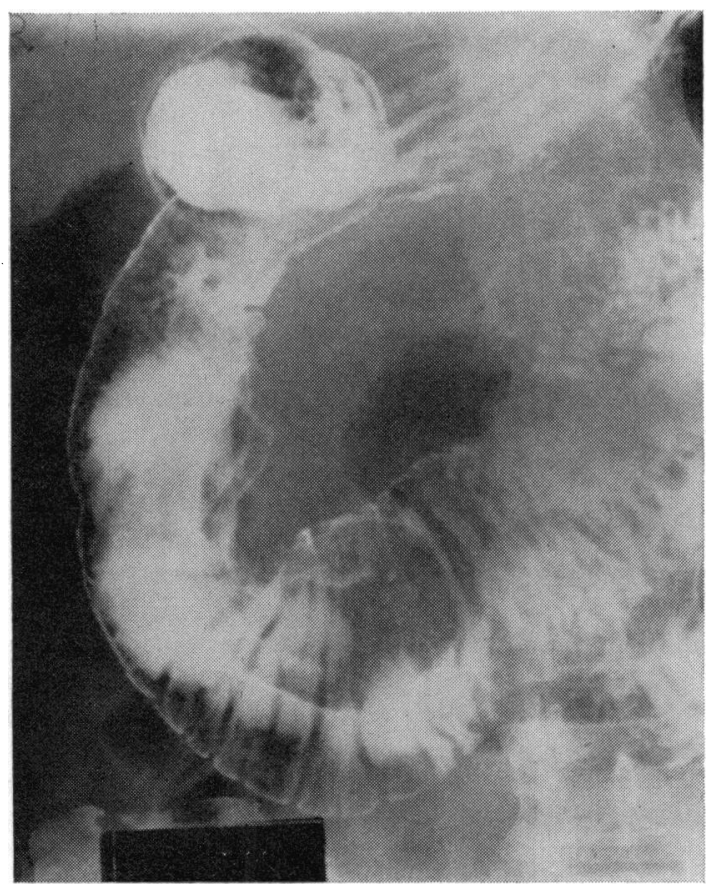

Fig. 4 Case 2: A hypotonic duodenogram shows that the polypoid mass is prolapsed further down. It did not become opaque after intravenous Biligrafin. 
$29.5 \%$. The first barium meal showed a polypoid mass with mucosal folds running along it in the duodenum (Fig. 3). It had considerable mobility and appeared to arise in the region of the ampulla, and this was confirmed by a hypotonic duodenogram (Fig. 4). After intravenous Biligrafin the bile ducts appeared normal and the polypoid mass was not opacified.

At operation (Mr T. Rowntree) no abnormality could be felt by external palpation of the duodenum, but when it was opened the cystic swelling was revealed within the lumen, and into it the pancreatic and biliary ducts opened. The cystic mass was marsupialized. The patient made an uninterrupted recovery.

Fragments of the polypoid structure composed of the duodenal mucosa were received which confirmed the polypoid nature of the abnormality (Dr R. A. Goodbody). There was also diffuse interstitial haemorrhage.

\section{Discussion}

Some 20 cases have been published similar to case 1 and it would seem that they are usually due to pulsion of a diaphragm. These diaphragms usually occur in the region of the ampulla and they may be incomplete. The aperture in them is usually eccentric. Duodenal mucosal stenosis is said to be common in mongols although only one actual diverticulum has been reported in a mongol (Curtis, Simpson, and Lowdon, 1965). Because of these features it is thought that they are congenital and due to faulty recession of the solid stage of the embryonic gut.

Many of the recorded cases were at first missed on the radiographs, but once seen the appearance is unmistakable. Our case is similar to the patient described by Levi and Kreel (1963) in that she presented at birth. She had, at that time, been diagnosed as having hypertrophic pyloric stenosis and patients with this condition are frequently not submitted to barium examination. There was a striking difference in the appearance of the diaphragm on the two occasions, once when acutely obstructed, and secondly when the acute stage had subsided.

It is not difficult to appreciate that when the diaphragm filled with debris and became propelled down the lumen the degree of obstruction was increased. The patients described by Borelli and Ruffato (1964) and by Levi and Kreel (1963) had also first presented in infancy. Two other cases have been described in which foreign bodies were retained in the diverticulum, one a corroded penny for many years (Meyer and Edgren, 1956). There have also been associated a lipoma (Moravec and Bednár., 1966), an annular pancreas (Mitchum and Coors, 1962), and

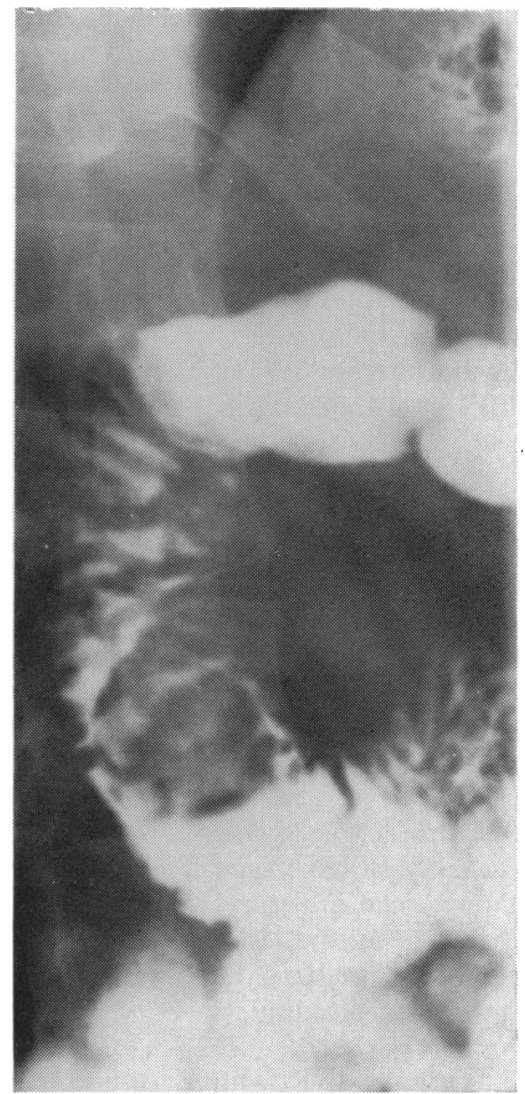

Fig. 5 Polypoid carcinoma of ampulla of Vater. The appearance closely resembles the choledochocele in Figures 3 and 4. The patient complained of postprandial epigastric pain, frequent loose motions, and loss of weight for four months. Histology - well differentiated adenocarcinoma of the ampulla.

acute pancreatitis (Nance, Cocchiara, and Kinder, 1967). Fortunately virtually all these cases are referred to as intraluminal diverticula.

Alonzo-Lej, Rever, and Pessagno (1959) would classify our case 2 as an example of a congenital choledochal cyst of their third variety, that is, a choledochocele. In their thorough review of choledochal cysts they refer to five other examples of choledochoceles. They draw an analogy between this lesion and the ureterocele. The difficulty with this explanation is that in most of the cases, and in our case, there was no histological confirmation of biliary mucosa within the lesion.

The case published by Kaftori, Munk, Schramek, and Barzilai (1966) from Israel deserves a special mention, as they were successful in opacifying the choledochocele with Biligrafin. We were unsuccess- 
ful in this. Unlike the intraluminal diverticula, none of the choledochoceles has filled with barium. The $x$-ray differential diagnosis of this condition is from the hypertrophic folds described by Mendl and Sharp (1960) and from polypoid tumours of the duodenum (Fig. 5). Seven similar cases were found, and there was a bewildering number of synonymscyst of the ampulla of Vater (Brooks and Weinstein, 1943), enterogenous cyst of the duodenum (Gordimer and Bluestone, 1950), diverticulum of the common bile duct (Alden and Sterner, 1957), choledochocele (Wheeler, 1940), intraduodenal choledochal cyst (Serfas and Lyter, 1957), and intraluminal diverticulum (Kaftori et al, 1966).

In the case reported by Serfas and Lyter (1957) there were areas of variable histology lining the cyst and these included both duodenal and bile duct mucosa. In other example reported by Alden and Sterner (1957) the wall of the cyst included all the elements of the common bile duct. Because of this variability of the histological lining, in our opinion choledochocele is the appropriate name and gives an accurate impression of the structure of the defect.

The presentation of choledochocele is with abdominal pain, usually rather vague, and vomiting. Three of the patients had a history of jaundice and two had gallstones within the lesion, including one of those who had been jaundiced. Ours was the only patient with a history of bleeding.

We should like to thank Mr Rowntree for access to his operation notes and Dr P. Slatter and Mr White, of the Wessex Regional Department of Medical Illustration, for the illustrations.

\section{References}

Alden, J. F., and Sterner, E. R. (1957). Diverticulum of the common bile duct. Ann. Surg., 145, 269-270.

Alonso-Lej, F., Rever, W. B., Jr., and Pessagno, D. J. (1959). Congenital choledochal cyst with a report of 2 , and an analysis of 94 cases. Int. Abstr. Surg., 108, 1-30.

Borelli, G., and Ruffato, C. (1964). Diverticolo intraluminale del duodeno: presentazione di un caso. Radiol. med (Torino), 50, 872-876.

Brooks, B., and Weinstein, A. (1943). Cyst of the ampulla of Vater. Ann. Surg., 177, 728-734.

Curtis, G. T., Simpson, W., and Lowdon, A. G. R. (1965). Intraluminal diverticulum of the duodenum in a mongol. Clin. Radiol., 16, 289-291.

Gordimer, H., and Bluestone, L. (1950). Enterogenous cyst of the duodenum: a case report. Ann. Surg., 132, 1149-1153.

Kaftori, J. K., Munk, J., Schramek, A., and Barzilai, D. (1966). Intraluminal diverticulum of the duodenum, demonstrated by intravenous cholangiography. Brit. J. Radiol., 39, 388-290.

Levi, A. J., and Kreel, L., for Milne, M. D., and Levi, D. (1963). Congenital intraduodenal diverticulum. Proc. roy. Soc. Med., 56, 168-170.

Mendl, K., and Sharp, M. E. (1960). Redundant duodenal mucosal folds and retrograde prolapse through the pylorus. Brit. J. Radiol., 33, 36-42.

Meyer, A. C., and Edgren, D. C. (1956). Duodenal obstruction by an intraluminal diverticulum. Arch. Surg., 73, 1058-1059.

Mitchum, W. R., and Coors, G. A. (1962). Intraluminal diverticulum of the duodenum. Brit. J. Radiol., 35, 499-500.

Moravec, R., and Bednáf, F. (1966). Intraluminal duodenal diverticulum. (Czech). Cesk. Radiol., 20, 253-255.

Nance, F. C., Cocchiara, J., and Kinder, J. L. (1967). Acute pancreatitis associated with an intraluminal duodenal diverticulum. Gastroenterology, 52, 544-547.

Serfas, L. S., and Lyter, C. S. (1957). Choledochal cyst. Amer. J. Surg., 93, 979-989.

Wheeler, W. I. de C. (1940). An unusual case of obstruction to the common bile-duct (choledochocele?). Brit. J. Surg., 27, 446-448. 